\title{
Adult dental health survey 2009: association between oral health outcomes and living arrangements of older adults in the UK.
}

AMINU, A.Q.

2019 
Title:

ADHS 2009: Association between oral health outcomes and living arrangements of older adults in the UK.

Abodunrin Q. Aminu

a.aminu@rgu.ac.uk

Robert Gordon University 


\section{Abstract}

Introduction: Considering the growing ageing populations and the impact of oral health in the well-being of older adults, there is a need for understanding dental care utilisation among this group. The objective of this study was to examine the relationship between living arrangements, oral health status and dental care utilisation of older adults in the UK.

Design: In this study, complete case analyses were carried out for the Adult Dental Health Survey (ADHS) 2009 wave including 1,251 older adults aged 75 years and over. Logistic regression analyses were carried to explore relationship between living arrangements and oral health outcomes of older adults.

Results: Findings from this study show that almost half (45.2\%) of the study population were living alone as at the time the ADHS (2009) data was collected. At $P<0.05$, older adults living alone were more likely to have a denture $(\mathrm{OR}=1.40,95 \% \mathrm{CI} 1.09,1.79)$, poor self-rated oral health status $(\mathrm{OR}=1.28,95 \%$ CI 1.00, 1.64) and poor dental care attendance $(\mathrm{OR}=1.6095 \%$ CI 1.35, 2.15) compared to those that lived with someone.

Conclusions: Living arrangements as a form of social support seems to play a role in understanding the accessibility of dental care to older adults.

Keywords: Aged, Dental care for Aged, Health Services for the Aged, Housing for the Elderly 
The increasing populations of older adults in many countries have already been documented, and the future projections for older populations are well apprehended [1]. It has been reported that the UK population is steadily growing older [1]. For instance, the Office for National Statistics (ONS) reported that the population of older adults age 65 years and over in the UK increased over a 25years period (1991-2016) from 9.1million to 11million people accounting for $15.8 \%$ of the total population [2]. The ONS projected that this demography is even expected to change with further increase in the next 50years, and population of older adults moving up to 20.6 million making up $26 \%$ of the UK population. The correlation between chronic diseases and ageing, makes it important for health and social care to be designed in a way to address the specific needs of the ageing societies. In the recent past, science has been able to significantly reduce the presence of acute infectious diseases thereby leading to increase in life expectancy [2]. However there is a paradigm shift towards increase in chronic illnesses, yet many healthcare systems have not really adjusted to this reality [3][4]. For instance, chronic diseases account for up to $80 \%$ of mortality and $90 \%$ of morbidity in the world today [3]. Due to this dramatic change in illness pattern and changing population dynamics, there is a need for change from acute care to chronic care while focusing on healthcare delivery. Oral health as a component of general health can also impact the quality of life of older adults. This is because population ageing may also mean that older adults are able to keep their teeth much longer than before [5]. For instance, older adults are now more at risk of oral diseases such as dental caries, gingivitis and periodontitis, and there is a significant increase in dental care utilisation among dentate older adults in the UK [6].

Living arrangements has also been identified to precipitate some factors that influence health of older adults and provide a link towards understanding the distribution of health outcomes among the ageing society. For example, family members or co-habitants have been known to play significant role in reducing dental anxiety and reinforcing positive dental perceptions [7]. 
These perceptions may determine the attitude of individuals towards dental treatment and consequently their oral health outcomes.

Despite the emphasized importance of social support on health outcomes in older adults, there is paucity of research that explored the influence of living arrangements on older adults' oral health outcomes [8]. More importantly, reports from the ONS suggest that many older adults may begin to live alone as a result of an increasing life expectancy and rate of divorce among these individuals [9]. It is therefore expected that changing demography and family structure may have a negative impact on the oral health status and dental care utilisation among older adults in the UK. In the present study it is hypothesized that living together with someone in a household will increase the chances of dental care utilisation and good oral health status of older adults in the UK.

This study aims to explore the association between living arrangements and some factors related to oral health, especially amongst older adults living alone in the UK

\section{Materials and Methods}

This study is a secondary data analysis of the 2009 Adult Dental Health Survey (ADHS) collected in the UK. The ADHS 2009 data was accessed through the UK data archive and the study was originally approved by the researcher's previous affiliation (University of Southampton ethics committee).

Study Population:

The ADHS data is a nationally representative survey of dental health carried out every ten years since 1968 and the 2009 survey is the fifth in the series. The ADHS, a survey commissioned by the NHS Information Centre for health and social care, was conducted in consortium with Department of Health, Social Services and Public Safety in Northern Ireland, the Welsh 
Assembly Health Department, and Department of Health in England and managed by the Office for National Statistics [10]. The data for the ADHS 2009 survey were collected from all sampled households with adults aged over 16 years using interviewer administered questionnaire ( $n=11,380)$. However, out of this number of respondents, 6,469 adults aged 16 years and over who had at least one natural tooth completed the clinical examination. The response rate for individual within the households was $84 \%$ and the overall household response rate was $60 \%$. This gave the survey the record of the largest epidemiological survey of dental health of the adult population in the United Kingdom [10].

In this study, data from respondents aged 75 years and over that participated in the ADHS (2009) interview were examined $(n=1254)$.Complete case analyses were carried out, which means that only respondents with complete data of the living arrangements and oral health outcomes for the control variables (age, gender, educational qualification and smoking status) were included in the analytical sample. Therefore, 3 respondents with missing information on the educational qualification were excluded from the analyses and so the analyses were conducted using the sample size $(n=1251)$.

Age 75 years was adopted as a threshold for this study based on the ONS life expectancy at birth (male 79.1 and female 82.8) of the UK population [11], using the Norman Ryder's theory of defining old age at a threshold level of 10 or $<10$ years Real Life Expectancy [12].This alternative definition of old age takes into consideration the improvements in health and life expectancies across the population which is not usually accounted for using chronological ages.

Key variables and Data Analysis: 
The Andersen's predictive factors (predisposing, enabling and need factors) was utilised in this study as it was used by previous studies to explain the pattern of healthcare utilisation [7, 13 \& 14]. This is because the model provided early understanding of how support system interacts with individual characteristics to predict health-seeking behaviors [15]. The model is also flexible to modification and appropriate for gerontological studies [16].

For the purpose of this study, the outcomes variables explored against the living alone status of the respondents were selected based on $100 \%$ responses in the dataset to ensure complete case analyses. By doing so, the author aimed to reduce the effect of outliers on the direction of association between the variables [17]. These variables were further categorized to fit into the Andersen predictive factors in line with previous studies [14] and as described by Andersen in his popular work on factors that affect healthcare utilisation [13].

Predisposing Factors: These factors include information about socio-demographic characteristics and health behaviours [18]. The variable on Age was categorized into: $1=75$ 84 years; 2= 85 years and over. Gender in the dataset was coded into 1: Male and 2: Female and the variable that described the smoking status 'Ever smoked' of the respondents was coded 1: Yes 2: No.

Enabling Factors: Living arrangements (living alone status) was defined by the household size: that is, the household with one individual represented Yes= living alone and household with more than one person represented No = living with someone. This is in accordance with the definition of the living arrangements of older adults in previous studies [7, 8].Educational qualification was assessed by whether the respondents' possess educational qualification at the degree level or below. The educational status was dichotomized into $1=$ Degree level and 2= Below degree. 
Need Factors: As a modification to the Andersen's model, this study utilised the need factors as outcome variables. The variables on the "denture status" and "self-reported oral health" were used to measure the oral health status of older adults in the UK. The Denture status was assessed by the respondents' answers to a question on denture “do you have a denture” and this variable was coded 1; Yes and 2; No. Furthermore, self-reported oral health variable in the ADHS (2009) dataset was categorized into Very Good, Good, Fair, Bad and Very Bad. In this study, the researcher dichotomized this variable into 1= Very Good/Good, 2= Fair/Bad/Very Bad.

Use of Healthcare Services: Dental care utilisation was assessed by the respondents' frequency of use of dental facilities. This variable was categorized into $1=$ at least every 6 to 12 months, $2=$ less frequent than every 12 months.

Descriptive analyses were conducted to investigate the distribution of the socio-demographic characteristics, explanatory variable (Living alone status) and oral health outcomes among the older adults in the analytic sample. Bivariate analyses were carried out to identify suitable variables for multivariate analyses. Logistic regression analyses were conducted to predict the likelihood of the explanatory variable to account for the variations in the oral health status and dental care utilisation of the studied population. The researcher initially examined the unadjusted relationship between the living alone status and each of the outcome variables, after which additional analyses were conducted to include the control variables (age, sex, education and smoking status). The number of included cases in each of the regression analyses, is dependent on the number of valid responses to the outcome variables. The researcher examined for collinearity bias among the predictors by conducting multi-collinearity test. The Variance Inflation Factor was less than 10 and the Tolerance value was greater than 0.1 , which means that there is no multi-collinearity problem in the regression models [17]. Data analysis was 
conducted using Statistical Package for Social Sciences (SPSS) version 21 and $P<0.05$ was considered statistically significant.

\section{Results}

The descriptive statistics carried out shows the distribution of the socio-demographic characteristics and the oral health outcomes of respondents in this study (Table 1). Almost half (45.2\%) of the study population were living alone at the time this data was collected.

The logistic regressions also indicated that at $P<0.05$, older adults living alone were more likely to have poor dental-care attendance (OR= 1.60 95\% CI 1.35, 2.15) compared to those that lived with someone (Table 4). Although the results also indicated that older adults living alone were likely to have reported poor self-rated oral health and have denture, the adjusted models confirmed that this could have been as a result of the cofounders. It can be observed in Tables 2 and 3 that the relationship between the living alone status of the respondents' loss significance after the age, gender, smoking status and educational status were included in the analyses.

\section{Discussion}

This study confirms the hypothesis, and it also corroborates existing data that link social supports and utilisation of healthcare services. The results show that older adults living with someone in the UK utilised dental care more frequently, and have good oral health status compared to those living alone. These might be as a result of supports such as physical, financial, mental and/or motivational supports available to older adults through their household members [8, 9]. It may also represent improvement in health care delivery in the UK in the $21^{\text {st }}$ century [18]. Some other factors that have been reportedly associated with low utilisation of dental care by older adults include co-morbidities, low compensation for dentists treating older 
adults and inadequate knowledge of geriatric dentistry [19]. This study identified that living arrangements might play a crucial role about oral health related decisions concerning when to visit a dentist. For instance, older adults may access financial and physical support from household members in order to keep their dental appointments and also to seek preventative dental treatment. Another possible pathway by which living arrangements is associated with dental-care utilisation is through oral health awareness [20]. This is because household members may influence the dental perception of older adults by reinforcing knowledge of oral health care and by encouraging health-seeking behaviours.

Denture wearing has been described as an appropriate surrogate for measuring oral health status because it relates to the degree of tooth loss [14, 21 - 22]. Similar to the report from the previous wave (1998) of the ADHS [8], the result of this study indicated that older adults living alone were likely to have a denture. McGrath and Bedi suggested that this outcome was likely due to lack of supports from their household members to carry out basic oral hygiene practices like teeth brushing or dental flossing necessary to maintain good oral health. Unlike the other studies, the present study suggests that some percentages of the predicted outcomes could have been accounted for by the cofounders (see Table 2). It can also be observed from this study that older adults in the UK may be keeping their natural teeth much longer. This is because the percentage of older adults that had a denture in this study was lesser than those recorded for a younger population in a previous study by McGrath and Bedi [8]. While this may represent an improvement in the NHS dental coverage in the twenty-first century [23, 24], it also confirms that there might be a need for a futuristic approach to address the impending oral health needs of the UK older adult population due to the possibility of persistent oral diseases at a later stage in old age.

Additionally, this study indicated that most respondents had a positive perception of their oral health status, which is consistent with findings from findings from previous studies [7,8 and 
14]. This study hypothesised that older adults living alone may be predisposed to poor psychological well-being. This is because loneliness or lack of social interactions can negatively impact self-perception about their general and oral health [7, 25 \& 26]. For example, older adults living alone may not likely be motivated to see a health professional when they have dental pain and may be unable to get help to manage their illness. In addition, it has been discussed in previous studies that people in later life may be using their poorly performing age peers as a reference [27-29], thus having a higher rating of their (oral) health and wellbeing. Nevertheless, findings from this study indicated that living arrangements is not a good predictor of self rated oral health perception. Introduction of cofounders into the analyses affected the significance of the association between self-rated oral health and the living status of older adult population in the UK negatively.

It is important to discuss the role of cofounders in the outcome of this study. It was observed that introduction of variables such as age and educational qualification, and habit such as smoking influenced the strength of association observed between living arrangements and oral health outcomes. Previous authors who have established a link between frailty and ageing suggested that it is expected that people become frailer in later life [30-32]. This may eventually mean that it becomes more difficult for them to access care due to disabilities. For instance, it has been largely established that denture wearing is more pronounced among the older population compared to the younger populations. Also, educational qualification as a proxy of socioeconomic status can greatly influence dental-care utilisation and health outcomes [33]. Vulnerable older adults with low social status are not likely to attend dental care due to the associated cost of treatment. This is important for two reasons: firstly, because it is not all social supports that include finances, and secondly because most advanced dental procedures are not free for older adults under the NHS [34]. Furthermore, this study identified that smokers had poor dental attendance. This may be because individuals that smoke cigarette will likely not 
visit the dental facilities in order to avoid counselling towards withdrawal from the smoking habit.

Despite its resourcefulness, this study is limited in some ways, which may be necessary for consideration while its findings are being applied. One of the limitations of this study is that it is limited to cross sectional findings and so may not account for time effect. Time effect may create bias and it is one of the disadvantages of cross-sectional studies [35]. For instance, attitude towards the use of dental facilities may have been influenced by timely events such as introduction of new dental-care service policies.

The limitation of this study can also be associated with the inability to examine the impact of social relationship or emotional aspect of living arrangements on the oral health status and dental care utilisation of older adults in the UK. Although, it is intended in this study to assess emotional aspect of social support but it was not possible due to data limitations. This is important because the relationship between the household members may be linked to oral health related decisions that can influence oral health status and dental care utilisation. For example, older adults living with their children or spouse may get direct support towards the utilisation of dental facilities compared to those living with other people [14].

Due to data limitations, this study was not able to control for the impact of disabilities that could have influenced dental care attendance. This is important because social supports available to older adults may have been channelled towards other morbidities instead of dental care. Furthermore, disabilities that limit physical movements may likely affect dental attendance of older adults, thereby creating an aggravated effect of living arrangements on the pattern of dental care utilisation of older adults in the UK. That is, older adults living alone may visit the dentist less frequently not because they lack support, but rather as a result of an illness that limits their movement. Also, research has suggested that limitations in the activities 
of daily living may influence oral health status of older adults [36]. For instance, physical or mental disabilities can limit the frequency or quality of oral hygiene practices, thus leading to deterioration of oral health.

\section{Conclusion}

This present study indicates that living arrangements as a form of social support seems to play a role in understanding the accessibility of dental care to older adults. Therefore, policy makers should consider living arrangements and accessibility of care when designing health schemes for the older population.

Competing interest: None declared.

Author's contributions: Author fulfilled the International Committee of Medical Journal Editors (ICMJE) criteria for authorship.

Acknowledgements: Appreciation goes to the UK data archive service for granting the permission to access the Adult Dental Health Survey 2009 wave. The author also wishes to appreciate Prof. Butali Azeez and Prof. Leo Marchini both of the University of Iowa for their Mentorship and secondary review of the manuscript respectively. 
Table1: Statistics of respondents' socio-demographic characteristics, oral health status and dental care utilisation

\begin{tabular}{|c|c|c|}
\hline Variables & $\mathbf{n}$ & valid percent \\
\hline \multicolumn{3}{|l|}{ Living alone status } \\
\hline Living alone (Yes) & 566 & 45.2 \\
\hline Living with someone (No) & 685 & 54.8 \\
\hline \multicolumn{3}{|l|}{ Age group } \\
\hline 75-84 years & 1010 & 80.7 \\
\hline 85 years and over & 241 & 19.3 \\
\hline \multicolumn{3}{|l|}{ Gender } \\
\hline Male & 566 & 45.2 \\
\hline Female & 685 & 54.8 \\
\hline \multicolumn{3}{|l|}{ Educational qualification } \\
\hline Degree & 459 & 36.7 \\
\hline Below degree & 572 & 63.3 \\
\hline \multicolumn{3}{|l|}{ Ever Smoked } \\
\hline Yes & 745 & 59.6 \\
\hline No & 506 & 40.4 \\
\hline \multicolumn{3}{|l|}{ Have Denture } \\
\hline No & 363 & 29 \\
\hline Yes & 888 & 71 \\
\hline \multicolumn{3}{|l|}{ Self-rated oral health } \\
\hline Good/Very good & 877 & 70.4 \\
\hline Fair/Bad/Very bad & 369 & 29.6 \\
\hline \multicolumn{3}{|l|}{ Dental Attendance } \\
\hline Every 6 to 12 months & 676 & 56.3 \\
\hline Less frequent than 12 months & 524 & 43.7 \\
\hline
\end{tabular}


Table 2: Odd ratios of having a denture by respondents' living arrangements (including control variables)

\begin{tabular}{|c|c|c|c|c|c|}
\hline Variables & $\begin{array}{l}\text { Model 1- } \\
\text { Unadjusted } \\
\text { OR (95\% CI) }\end{array}$ & $\begin{array}{l}\text { Model } 2 \\
\text { OR (95\% CI) }\end{array}$ & $\begin{array}{l}\text { Model } 3 \\
\text { OR (95\% CI) }\end{array}$ & $\begin{array}{l}\text { Model } 4 \\
\text { OR (95\% CI) }\end{array}$ & $\begin{array}{l}\text { Model } 5 \\
\text { OR (95\% CI) }\end{array}$ \\
\hline \multicolumn{6}{|l|}{$\begin{array}{l}\text { Living alone } \\
\text { status }\end{array}$} \\
\hline No & 1.00 & 1.00 & 1.00 & 1.00 & 1.00 \\
\hline Yes & $\begin{array}{l}1.40 \\
1.79)\end{array}$ & $1.29(1.00-1.66)$ & $1.20(0.92-1.56)$ & $1.12(0.86-1.47)$ & $1.10(0.84-1.44)$ \\
\hline \multicolumn{6}{|l|}{ Age group } \\
\hline $\begin{array}{l}85 \text { years and } \\
\text { over }\end{array}$ & & 1.00 & 1.00 & 1.00 & 1.00 \\
\hline $75-84$ years & & $0.58(0.41-0.83)$ & $0.59(0.41-0.84)$ & $0.62(0.43-0.88)$ & $0.63(0.44-0.90)$ \\
\hline \multicolumn{6}{|l|}{ Gender } \\
\hline Male & & & 1.00 & 1.00 & 1.00 \\
\hline Female & & & $0.71(0.55-0.92)$ & $0.74(0.57-0.96)$ & $0.64(0.49-0.84)$ \\
\hline \multicolumn{6}{|l|}{$\begin{array}{l}\text { Educational } \\
\text { qualification }\end{array}$} \\
\hline Below degree & & & & 1.00 & 1.00 \\
\hline Degree & & & & $0.39(0.30-0.50)$ & $0.39(0.30-0.51)$ \\
\hline \multicolumn{6}{|l|}{$\begin{array}{l}\text { Smoking } \\
\text { status }\end{array}$} \\
\hline No & & & & & 1.00 \\
\hline Yes & & & & & $1.71(1.31-2.23)$ \\
\hline $\begin{array}{l}\text { Model sample } \\
\text { size }\end{array}$ & 1251 & 1251 & 1251 & 1251 & 1251 \\
\hline $\begin{array}{l}\text { Pseudo } R \\
\text { square }\end{array}$ & 0.008 & 0.019 & 0.027 & 0.085 & 0.10 \\
\hline
\end{tabular}

- Data in bold indicates statistical significance at $P<0.05$ 
Table 3: Odd ratios of poor self-rated oral health by respondents' living arrangements (including control variables)

\begin{tabular}{|c|c|c|c|c|c|}
\hline Variables & $\begin{array}{l}\text { Model 1- } \\
\text { Unadjusted } \\
\text { OR (95\% CI) }\end{array}$ & $\begin{array}{l}\text { Model } 2 \\
\text { OR (95\% CI) }\end{array}$ & $\begin{array}{l}\text { Model } 3 \\
\text { OR (95\% CI) }\end{array}$ & $\begin{array}{l}\text { Model } 4 \\
\text { OR (95\% CI) }\end{array}$ & $\begin{array}{l}\text { Model } 5 \\
\text { OR (95\% CI) }\end{array}$ \\
\hline \multicolumn{6}{|l|}{$\begin{array}{l}\text { Living alone } \\
\text { status }\end{array}$} \\
\hline No & 1.00 & 1.00 & 1.00 & 1.00 & 1.00 \\
\hline Yes & $\begin{array}{l}1.28 \\
1.64)\end{array}$ & $1.22(0.95-1.56)$ & $1.25(0.97-1.62)$ & $1.20(0.93-1.56)$ & $1.20(0.93-1.56)$ \\
\hline \multicolumn{6}{|l|}{ Age group } \\
\hline $\begin{array}{l}85 \text { years and } \\
\text { over }\end{array}$ & & 1.00 & 1.00 & 1.00 & 1.00 \\
\hline $75-84$ years & & $0.73(0.54-1.00)$ & $0.73(0.54-0.99)$ & $0.76(0.56-1.03)$ & $0.76(0.56-1.03)$ \\
\hline \multicolumn{6}{|l|}{ Gender } \\
\hline Male & & & 1.00 & 1.00 & 1.00 \\
\hline Female & & & $1.12(0.87-1.45)$ & $1.16 \quad(0.90-$ & $1.14(0.88-1.48)$ \\
\hline $\begin{array}{l}\text { Educational } \\
\text { qualification }\end{array}$ & & & & $0.150)$ & \\
\hline Below degree & & & & 1.00 & 1.00 \\
\hline Degree & & & & $0.53(0.43-0.74)$ & $0.57(0.44-0.75)$ \\
\hline \multicolumn{6}{|l|}{$\begin{array}{l}\text { Smoking } \\
\text { status }\end{array}$} \\
\hline No & & & & & 1.00 \\
\hline Yes & & & & & $1.06(0.82-1.38)$ \\
\hline $\begin{array}{l}\text { Model sample } \\
\text { size }\end{array}$ & 1246 & 1246 & 1246 & 1246 & 1246 \\
\hline $\begin{array}{l}\text { Pseudo } R \\
\text { square }\end{array}$ & 0.005 & 0.009 & 0.010 & 0.02 & 0.10 \\
\hline
\end{tabular}

- Data in bold indicates statistical significance at $P<0.05$

- Analyses excluded 5 missing values in the outcome variable. [Dependent variable 1= Very Good/Good, 2= Fair/Bad/Very Bad] 
Table 4: Odd ratios of poor dental attendance by respondents' living arrangements (including control variables)

\begin{tabular}{|c|c|c|c|c|c|}
\hline Variables & $\begin{array}{l}\text { Model 1- } \\
\text { Unadjusted } \\
\text { OR (95\% CI) }\end{array}$ & $\begin{array}{l}\text { Model } 2 \\
\text { OR (95\% CI) }\end{array}$ & $\begin{array}{l}\text { Model } 3 \\
\text { OR (95\% CI) }\end{array}$ & $\begin{array}{l}\text { Model } 4 \\
\text { OR (95\% CI) }\end{array}$ & $\begin{array}{l}\text { Model } 5 \\
\text { OR (95\% CI) }\end{array}$ \\
\hline \multicolumn{6}{|l|}{$\begin{array}{l}\text { Living alone } \\
\text { status }\end{array}$} \\
\hline No & 1.00 & 1.00 & 1.00 & 1.00 & 1.00 \\
\hline Yes & $\begin{array}{l}1.60 \\
2.15)\end{array}$ & $1.59(1.25-2.01)$ & 1.57 (1.23-1.99) & 1.45 (1.13-1.87) & 1.44 (1.11-1.85) \\
\hline \multicolumn{6}{|l|}{ Age group } \\
\hline $\begin{array}{l}85 \text { years and } \\
\text { over }\end{array}$ & & 1.00 & 1.00 & 1.00 & 1.00 \\
\hline $75-84$ years & & $0.64(0.48-0.86)$ & $0.64(0.48-0.87)$ & $0.69(0.50-0.94)$ & $0.69(0.50-0.94)$ \\
\hline \multicolumn{6}{|l|}{ Gender } \\
\hline Male & & & 1.00 & 1.00 & 1.00 \\
\hline Female & & & 0.93 (0.73-1.19) & $1.02(0.79-1.31)$ & $0.95(0.73-1.23)$ \\
\hline \multicolumn{6}{|l|}{$\begin{array}{l}\text { Educational } \\
\text { qualification }\end{array}$} \\
\hline Below degree & & & & 1.00 & 1.00 \\
\hline Degree & & & & $0.27(0.21-0.36)$ & $0.28(0.21-0.36)$ \\
\hline \multicolumn{6}{|l|}{$\begin{array}{l}\text { Smoking } \\
\text { status }\end{array}$} \\
\hline No & & & & & 1.00 \\
\hline Yes & & & & & 1.31 (1.01-1.69) \\
\hline $\begin{array}{l}\text { Model sample } \\
\text { size }\end{array}$ & 1200 & 1200 & 1200 & 1200 & 1200 \\
\hline $\begin{array}{l}\text { Pseudo R } \\
\text { square }\end{array}$ & 0.02 & 0.03 & 0.03 & 0.13 & 0.14 \\
\hline
\end{tabular}

- Data in bold indicates statistical significance at $P<0.05$

- Analyses excluded 51 missing values in the outcome variable. [Dependent variable $1=$ Dental visit every 6 to 12 months, $2=$ Less frequently, above 12months] 


\section{References}

1. United Nations. World Population Prospects: The 2017 Revision. New York: United Nations, 2017.

2. Office for National Statistics ONS, Living longer - how our population is changing and why it matters. Available from: https://www.ons.gov.uk/peoplepopulationandcommunity/birthsdeathsandmarriages/ag eing/articles/livinglongerhowourpopulationischangingandwhyitmatters/2018-08-13 [Accessed 3/Oct/2018]

3. Goldsmith J. The paradigm shift: Transforming from an acute to chronic care model. Decisions in Imaging Economics. 1990; 14:13-9.

4. Whelan J. WHO calls for countries to shift from acute to chronic care. BMJ: British Medical Journal. 2002 May 25; 324(7348):1237.

5. Vargas CM, Kramarow EA, Yellowitz JA. The oral health of older Americans. Hyattsville, MD: Centers for Disease Control and Prevention, National Center for Health Statistics; 2001 Mar.

6. Berkman LF Glass, T. Social integration, social networks, social support, and health. Social epidemiology. 2000; 2(1): 137-173.

7. Burr JA, Lee, HJ. Social Relationships and Dental Care Service Utilisation Among Older Adults. Journal of Aging and Health. 2013; 25(2): 191-220.

8. McGrath C. and Bedi R. Influences of social support on the oral health of older adults in Britain. Journal of Oral Rehabilitation. 2002; 29 (10): 918-922.

9. Office for National Statistics. Divorce, 2012. Available from: https://www.ons.gov.uk/peoplepopulationandcommunity/birthsdeathsandmarriages/di vorce/bulletins/divorcesinenglandandwales/2014-02-06 [Accessed 13/3/2017]

10. Steele J, O’Sullivan I. Executive summary: adult dental health survey. 2011, Leeds: NHS Information Centre for Health and Social Care.

11. Office for National Statistics. Life Expectancy, 2015. Available from: https://www.ons.gov.uk/peoplepopulationandcommunity/birthsdeathsandmarriages/lif eexpectancies [Accessed 3/10/2018]

12. Ryder NB. Notes on stationary populations. Population Index. 1975, 1: 3-28.

13. Andersen RM. Revisiting the behavioural model and access to medical care: does it matter? Journal of health and social behaviour. 1995; 1-10.

14. Campo M, Yon Y. The influence of social support on dental care utilization among older adults in Canada. Canadian Journal of Dental Hygiene. 2014; 48(4): 147-157.

15. Andersen RM. National health surveys and the Behavioural Model of Health Services Use. Medical Care. 2008; 46(7): 647-653.

16. Willis R, Glaser K, Price D. Applying the Andersen behavioural model to informal support among Britain's ethnic minorities. Generations Review: British Society of Gerontology. 2007; 20.

17. Field A. Discovering statistics using IBM SPSS statistics. Sage; 2013. 
18. Glasby, J. Understanding health and social care. Bristol: The Policy Press (2012).

19. Poul Holm-Pedersen, Merete Vigild, Ina Nitschke and Douglas B. Berkey. Journal of Dental Education September 2005, 69 (9) 987-997

20. Petersen PE, Bourgeois D, Ogawa H, Estupinan-Day S, Ndiaye C. The global burden of oral diseases and risks to oral health. Bulletin of the World Health Organization. 2005; 83(9): 661-669.

21. Wong MC, McMillan AS. Tooth loss, denture wearing and oral health-related quality of life in elderly Chinese people. Community dental health. 2005; 22(3): 156-161.

22. Inukai M, Baba K, John MT, Igarashi Y. Does removable partial denture quality affect individuals' oral health? Journal of dental research. 2008; 87 (8):736-739.

23. Pascall G. Health and health policy. Oxford University press; 2007.

24. Glasby J. Understanding health and social care. Policy Press; 2012.

25. Rouxel P, Heilmann A, Demakakos P, Aida J, Tsakos G, Watt RG. Oral health-related quality of life and loneliness among older adults. European Journal of Ageing. 2016: 19.

26. Steele JG, Walls AW, Ayatollahi SM, Murray JJ. Dental attitudes and behaviour among a sample of dentate older adults from three English communities. British dental journal. 1996; 180(4): 131-136.

27. Kaplan G, Baron-Epel O. What lies behind the subjective evaluation of health status? Social science \& medicine. 2003, 30; 56(8): 1669-1676.

28. Morgan LA, Kunkel S. Aging, society and the life course. Springer Publishing Company; 2007.

29. Cockerham WC, Scambler G. Medical sociology and sociological theory. The new Blackwell companion to medical sociology. 2010; 29:3-26.

30. Fried LP, Tangen CM, Walston J, Newman AB, Hirsch C, Gottdiener J, Seeman T, Tracy R, Kop WJ, Burke G, McBurnie MA. Frailty in older adults' evidence for a phenotype. The Journals of Gerontology Series A: Biological Sciences and Medical Sciences. 2001, 1; 56(3): M146-57.

31. Song X, Mitnitski A, Rockwood K. Prevalence and 10-Year Outcomes of Frailty in Older Adults in Relation to Deficit Accumulation. Journal of the American Geriatrics Society. 2010,1; 58(4): 681-687.

32. Strandberg TE, Pitkälä KH, Tilvis RS. Frailty in older adults. European geriatric medicine. 2011, 31; 2(6): 344-355.

33. Sanders A. Social determinants of oral health: conditions linked to socioeconomic inequalities in oral health in the Australian population, 2007.

34. National Health Service. NHS dental services explained, 2015. Available from: http://www.nhs.uk/NHSEngland/AboutNHSservices/dentists/Pages/nhsdentalcharges.aspx [Accessed 2/9/2018]

35. Bryman A. Social research methods, 5th edition. Oxford University press; 2015.

36. Wu B, Plassman BL, Liang J, Remle RC, Bai L, Crout RJ. Differences in self-reported oral health among community-dwelling black, Hispanic, and white elders. Journal of aging and health. 2011, 1; 23(2): 267-288. 